\title{
Looking back across the life span: A life story account of the reminiscence bump
}

\author{
JUDITH GLÜCK \\ Alpen-Adria University Klagenfurt, Klagenfurt, Austria \\ AND \\ SUSAN BLUCK \\ University of Florida, Gainesville, Florida
}

\begin{abstract}
The reminiscence bump is a robust finding in the autobiographical memory literature: Adults recall more events from the second and third decades of life than from other periods. Berntsen and Rubin (2004; Rubin \& Berntsen, 2003) proposed a life script account of the reminiscence bump. We extend the life script account by taking a theory-based, life span developmental approach, proposing a life story account for the bump. This account predicts that events in the reminiscence bump are characterized not only by positive valence, but also by high perceived control and high perceived influence on later development. Predictions from the life story account were confirmed in analyses of 3,541 life events collected from 659 participants 50-90 years of age. Only highperceived-control positive events showed a reminiscence bump, and these events were rated as more influential on later development than were events showing any other combination of valence and perceived control. Findings are discussed in terms of a theoretical extension of the life script account embracing (1) principles of life span development and (2) the personal creation of a life story that helps to organize autobiographical memory.
\end{abstract}

One of the most robust findings in the autobiographical memory literature is that people recall a larger number of events from the second and third decades of their life than from other periods. This effect, the reminiscence bump (Rubin, Wetzler, \& Nebes, 1986), has been found using a variety of memory materials (e.g., Cohen \& Faulkner, 1988; Crovitz \& Schiffman, 1974; de Vries \& Watt, 1996; Fromholt \& Larsen, 1991, 1992). Thus, it occurs relatively independently of how participants are asked to recall events. ${ }^{1}$ Several accounts of why life event data produce this particular pattern have been proposed (e.g., Fitzgerald, 1996; Rubin, Rahhal, \& Poon, 1998).

A recent study showed a reminiscence bump for people's memories of their happiest, but not of their saddest or most traumatic, life events (Berntsen \& Rubin, 2002). This demonstration that only positive memories show the bump has moved theorizing in this area forward. Berntsen and Rubin (2002) compared the efficacy of five previously proposed theoretical accounts (i.e., cognitive processing, biological/maturational, actual event frequency, narrative/ identity, and life script) for explaining why a reminiscence bump occurs when happy events are recalled, but not for sad and traumatic events. Berntsen and Rubin (2002, 2004) argued that that a life script account best explains their data. The life script account suggests that the bump is a product of a particular strategy for searching memory when one's life is recalled. It assumes that people have an internalized culturally based script of the events that make up an expected, skeletal life course; this script acts as a template for the recall of life events in association with each life phase. According to this account, happy events are scripted as frequent in late adolescence/young adulthood (i.e., the bump years). Rubin and Berntsen (2003) argued that negative events are not part of life scripts and, therefore, follow a monotonically decreasing retention function, instead of a reminiscence bump (Berntsen \& Rubin, 2002, 2004). Berntsen and Rubin (2004) showed that when participants generate normative life scripts, the scripted events are largely positive and show a bump in the second and third life decades. Thus, they suggest that the reminiscence bump for happy events is the product of the use of a retrieval strategy, the life script, for recalling life events.

We extend the life script account of the reminiscence bump into a life story account embracing life span developmental theory (e.g., Havighurst, 1952; Levinson, 1986; Neugarten, 1968), which offers several building blocks for a more explanatory account of the reminiscence bump. In short, the life story account argues that the events in the reminiscence bump are retrieved not only because they are cued by normative life scripts, but also because they are individually memorable in as much as (1) the person has faced the developmental task of taking control of his or her life and (2) the individual later views these events

J. Glück, judith.glueck@uni-klu.ac.at 
as having had a strong influence on who he or she has become. Below, the extended account will be grounded in theoretical and empirical work from the life span developmental and autobiographical memory literatures.

\section{Life Span Developmental Theories}

In this section, a developmental framework will be reviewed that distinguishes different types of important life events, allowing for a clarification of the types of events that should produce bumps in recalled event distributions. Next, perceived control will be discussed as an important characteristic of developmentally normative events of the reminiscence bump age.

Types of important life events. Life span theorists have distinguished three types of events that structure the life course: normative age-graded events, history-graded events, and nonnormative events (Baltes, Reese, \& Lipsitt, 1980). Age-graded events normatively occur in a certain life phase across the population for biological (e.g., puberty) or sociocultural (e.g., school entry) reasons. History-graded events occur at a certain time in a particular culture (e.g., wars or natural catastrophes). They can have strong effects on individuals, which may differ depending on those individuals' age when the event occurred (Elder, 1998; Riley, 1987). Nonnormative events are neither developmentally nor historically typical (e.g., loss of a parent in childhood; Neugarten \& Hagestad, 1976), although they may have high salience and, thus, may be memorable to the individuals to whom they occur.

Age-graded events, which are recalled from one life phase across a large number of individuals regardless of their current age, produce patterns such as the classic reminiscence bump. Momentous history-graded events can produce history-related bumps - bumps that occur at the same historical time, but in different age periods for different cohorts of individuals (see, e.g., Conway \& Haque, 1999; Rubin \& Berntsen, 2003; Schrauf \& Rubin, 2001). In the present study, the majority of the participants had lived through the Third Reich and World War II (WWII) in Austria. Thus, we expected the classic reminiscence bump for age-graded events but, also, history-related bumps for negative events in time periods corresponding to the time of WWII. Nonnormative events that occur to individuals cannot produce reminiscence bumps across unselected samples because they are, by definition, not related to specific age phases or historical happenings affecting the entire sample.

Age-normative events of the reminiscence bump years: Taking control of one's life. What type of events are age normative in the reminiscence bump years according to life span theory, and what characteristics make them memorable? Several classic models of development (e.g., Havighurst, 1952; Levinson, 1986) describe the transition to young adulthood in terms of developmental tasks that involve making choices - about one's education, career path, life partner, and childbearing. These choices set the stage for life's later unfolding (Arnett, 2000). Even when later changes concerning one's choices occur (e.g., divorce), the original decision has still affected one's life course, and the resultant outcomes reflect trajecto- ries of one's (sometimes misguided) young adulthood decisions. $^{2}$

These developmental tasks require that individuals take control of their lives. Although perceived control is generally a source of positive affect (e.g., Bandura, 1997; Lachman \& Firth, 2004), the potential for exercising perceived control is relatively low in childhood, increases in adolescence, and stays stable across most of adulthood (Heckhausen, 1997). When asked for subjective criteria for being an adult, young adults consistently name "accepting responsibility for one's self" and "making independent decisions" as the most important criteria (Arnett, 2000; Dreher \& Dreher, 1991). Thus, the developmental tasks of young adulthood and the empirical evidence with respect to perceived control suggest that young adulthood is not simply a time of happy events. Instead, it is a time of positive instances of exercising control over one's life with respect to consequential life choices. To test this claim, the participants in the present study listed the important events in their lives and rated valence and perceived control for each. Berntsen and Rubin (2002), arguing that life scripts act as schematics that guide retrieval of normative positive events, predicted that only positive events should show the reminiscence bump. In contrast, the life story account predicts that only events that are positive but also high in perceived control will show the classic reminiscence bump.

\section{Organizing Elements of Life Stories}

Whenever autobiographical memories are analyzed, a second issue is relevant beyond considerations of how the life span is actually structured. By definition, remembering involves two time points: Memories are produced by individuals thinking about earlier time periods from their current vantage point in life. Events do not become part of the reminiscence bump only because they were perceived as important at the time they happened but because they are now, or still, perceived as important. That is, they are perceived as influential for the individual's development so that, when reflecting back on life, these events are more likely to be recalled. The influence of a past event on who an individual has become cannot be contained in a life script. It is an integral aspect of one's life story (McAdams, 1993).

The life story provides the most abstract level of organization in autobiographical memory (Bluck \& Habermas, 2001; Conway, Singer, \& Tagini, 2003). Personality theorists recognize that the life story combines remembered episodes with explanations of how one's life and personality have developed over time (Hooker \& McAdams, 2003). Bluck and Habermas (2000) described four different sources of coherence that individuals use to organize or structure the events of their lives into a life story: temporal coherence, thematic coherence (organizing events by overarching themes), the cultural concept of biography (a culture's normative idea of the major events in a life), and causal coherence (explaining events and personal developments in reference to previous events).

The cultural concept of biography is highly similar to what Berntsen and Rubin (2004) called a life script. However, when individuals recall their own life events, other 
forms of organization are also involved. In particular, the creation of causal coherence between experienced events and later events or later personal development is one crucial way that individuals tie their remembered life stories together (i.e., autobiographical reasoning, narrative processing; Singer \& Bluck, 2001). Specifically, life choice events that occur during the transition to young adulthood are likely to form an integral part of the life story in terms of the way that one repeatedly explains to both oneself and others how one's life has unfolded. Those early events in which one positively dealt with developmental tasks that required taking control of one's future life path are linked to one's current self through causal coherence. They are recalled particularly well because they have continued to influence one's development and have, therefore, been well integrated into one's life story (Martin \& Smyer, 1990). For clarity, note that individuals also create causal coherence for low-perceived-control events, such as the death of a parent. Such events, however, are not more typical in a particular life phase (i.e., young adulthood), so they do not produce a reminiscence bump across a sample.

\section{Embracing Developmental Theory: A Life Story Account of the Reminiscence Bump}

The account suggested here extends and differentiates Berntsen and Rubin's (2002) life script account of the reminiscence bump, which is based on retrieval of events though the use of a skeletal, normative life script. Our life story account suggests that it is not simply scripted happy events that form the reminiscence bump, but that the reminiscence bump events are of individual developmental significance. They are (1) events that are remembered as positive instances of having exerted control of one's life and (2) events that individuals feel have influenced their development across time.

Study design and predictions. In this study, participants from a large representative survey of 50- to 90 -yearold Austrians were asked to list up to 15 events that they considered most important in their life, to date them, and to rate them with respect to valence, perceived control, and influence on further development. We analyzed the life span distributions of these events from birth to age 50 . The first two predictions tested here replicate previous work: (1) As was found by Berntsen and Rubin (2002, 2004), only positive events should show a reminiscence bump; (2) as was found by Rubin and Berntsen (2003), as well as by other researchers, there should be history-related bumps for negative events in the age period in which each cohort lived through WWII. Extending the life script account to a developmentally grounded life story account encompasses the above predictions but also allows for additional predictions: (3) Of all the events recalled, only high-perceived-control, not low-perceived-control, positive events should show a reminiscence bump; (4) these high-perceived-control positive events should be viewed as more influential for one's development than are lowperceived-control or negative events; and (5) of events typically contained in life scripts, only those that are rated as positive and perceived as under high control will show the reminiscence bump.

\section{METHOD}

\section{Participants}

This study was conducted by the Austrian partner of the European Study of Adult Well-Being (ESAW), Department of Psychology, University of Vienna (Weber, Glück, Schäfer, Wehinger, Heiss, \& Sassenrath, 2005). As part of ESAW, a representative sample (stratified by age, gender, and residential area) of 2,255 communitydwelling Austrians from 50 to 90 years of age completed a survey in one or two interview sessions. Of these, the participants who had difficulty writing or difficulty completing the ESAW interview were not offered the Life Story Questionnaire used in the present study. The other participants were offered the questionnaire, and those who accepted it were asked to fill it out and mail it to the project staff. The questionnaires had individual identification numbers so that they could be linked to the other data collected in the ESAW interview without violating anonymity.

Two advantages of the mail procedure were that the questionnaire was self-paced, so the participants could spend time thinking about their responses, and that the mail survey encouraged individuals to reveal events that they might not have been comfortable discussing with an interviewer. The disadvantage of this procedure was that not all the participants completed the questionnaire. Of about 1,500 participants who were offered the Life Story Questionnaire, approximately 1,200 accepted it, and 765 filled it out and returned it by mail. To test for respondent selectivity, all cases for which all necessary information was available were analyzed. No substantial differences were evident between the three samples. The three groups did not differ by gender $\left[\chi^{2}(2)=2.14, p=.34\right]$ and selfrated health $[F(2,2035)=1.152, p=.32]$, but they did differ by residential area $\left[\chi^{2}(4)=23.38, p<.001\right]$, age $[F(2,2057)=3.02$, $p=.05]$, and years of education $[F(2,2024)=6.65, p<.01]$. The participants who returned the questionnaire were slightly younger (although not more than a year on average), had somewhat higher education (again, about a year on average), and were somewhat more likely to be from an urban area.

\section{Procedure}

At the end of the ESAW interview, the interviewer introduced the participants to the Life Story Questionnaire, telling them it was about how people look back on their own life. The interviewer reviewed the format of the questionnaire to ensure that the participants understood the questions. The participants were asked to fill out the questionnaire at their convenience and mail it back. In cases in which the ESAW interview took more than one session, the interviewer left the questionnaire with the participants after the first session and picked it up (in a sealed envelope) in the next session.

\section{Measures}

The Life Story Questionnaire on which the present study is based was collected as the first questionnaire in a set that also contained self-report measures of retrospective views of wisdom, foolishness, and regret, on the functions of autobiographical memory, and on personal life philosophies. Since all of these measures came after the Life Story Questionnaire, they were not expected to have affected the present findings.

The Life Story Questionnaire was developed on the basis of Rappaport's lifeline (Rappaport, Enrich, \& Wilson, 1985; see also de Vries, Blando, \& Walker, 1995). It involves listing up to 15 events or experiences that the participant views as most personally important in his or her life. The instructions emphasize that the participant should list events that he or she found personally important. For each event, the participants gave a brief description of the event (one to five words), indicated his or her age at the time the event occurred, and completed four 5-point Likert-type scales concerning the event: valence of the event (negative to positive), valence of later consequences of the event (negative to positive), perceived control over the event (none to complete), and influence of the event on who the participant had become (little to strong). Thus, the number of events 


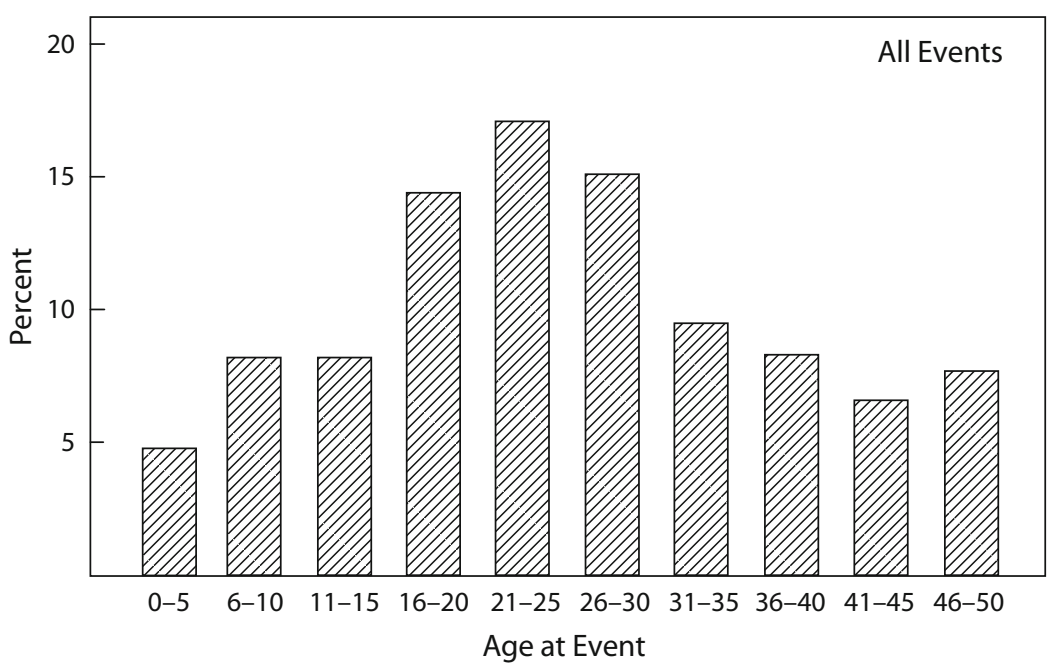

Figure 1. Life span distribution of all reported events.

produced, age at event, valence, perceived control, and perceived influence were directly available from the questionnaire data. Results concerning valence of later consequences will not be reported, since they were not relevant to the findings presented here.

Descriptions of the events were content analyzed by a trained coder. To establish intercoder reliability, a random $15 \%$ of the events were coded by a second coder; kappa was .87. In order to test the predictions regarding the history-related bump, one of the coding categories comprised war-related memories. Memories were coded as war related if they explicitly mentioned the Third Reich or WWII (e.g., bombings, war deaths, return of loved ones). Of all listed events, $4.8 \%$ were coded as war related. In addition, to test Prediction 5, all other events were assessed to establish whether they could be considered scripted events in terms of matching life script categories reported in Berntsen and Rubin's (2004) life script study (see Table 2 for codes).

\section{RESULTS}

Of the 765 participants, 710 listed at least one event in the Life Story Questionnaire (range $=1-15$ ). In total, these 710 participants reported 5,293 important life events, implying a mean of 7.5 events per participant $(S D=4.2)$. The age frequency distributions of life events are obviously limited by the participants' current age (e.g., a 60-year-old participant cannot report events from age $65)$. Therefore, because the youngest participants were 50 , the following analyses include only those events that occurred before the participants were 50 years of age. In addition, we only included events for which a single time or year was given. In total, 3,541 events from 659 participants were included in the analyses. The analyses do not include 201 events for which no age at the time of the event was provided, 912 events that were not particular events but described extended life periods, and 719 events that occurred after age $50 .^{3}$ Age information was missing for 8 participants.

For some of the following analyses, the participants were divided into three age groups: $50-59$ years $(N=$ 285), 60-69 years $(N=195)$, and $70-90$ years $(N=$ 171 ). The oldest age group covered a 20 -year, instead of a 10-year, span because only 43 participants were 80 years and older. There was a significant difference between the three age groups in average number of reported events $[F(2,650)=10.80, p<.001]$; post hoc Tukey tests showed that the 70- to 90 -year-old participants reported significantly fewer events $(M=4.4, S D=3.1)$ than did the 50- to 59-year-olds ( $M=5.8, S D=3.4)$ and the 60 - to 69 -year-olds $(M=5.6, S D=3.2)$.

The methodology used in the present study allowed the participants to differ in the number of events that they reported. Thus, if all events are used in analyses, the independence assumption required by statistical tests such as $\chi^{2}$ is violated. For descriptive purposes, we still will report figures and statistical analyses for the whole sample of 3,541 events. However, each result is validated using a bootstrap-type analysis: One hundred random samples of $N=659$ events were drawn so that each sample contained 1 event from each participant. For each analysis, the median $\chi^{2}$ value and its $p$ value, the average sample size, and the mean and standard deviation across the bootstrap samples of the appropriate effect size statistic (Cohen's $w$ for tests against a uniform distribution, $\Phi$ for $2 \times 2$ tables, and Cramer's $V$ for larger tables) are reported. The effect size statistics were normally distributed across the 100 samples in all cases.

Figure 1 shows the age distribution of all 3,541 events, using 5-year intervals. In line with other studies, the figure shows a clear reminiscence bump from age 15 to 30 years. Due to the smaller numbers of events when the sample was broken up by valence and perceived control, 10-year intervals, instead of 5-year intervals, were used in all the following analyses.

\section{Life Span Distribution of Positive and Negative Events}

Events that received a rating of 4 or 5 on the valence scale were coded as positive; events that had been rated 1 or 2 were coded as negative. Overall, the participants reported significantly more positive than negative events 

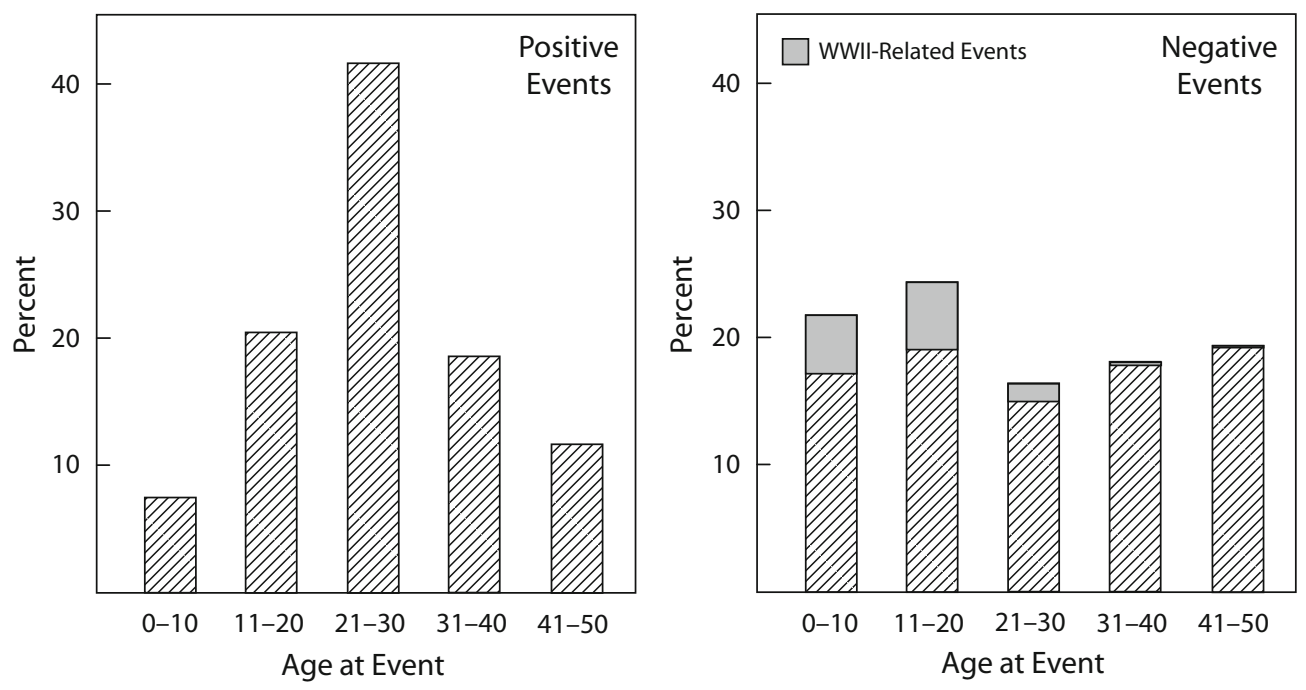

Figure 2. Life span distributions of positive and negative events.

$\left[\chi^{2}(1)=296.01, p<.001 ; 100\right.$ bootstrap samples: median $\chi^{2}(1)=55.70, p<.001$, mean $n=577$, mean Cohen's $w=.31, S D=.03]$. Figure 2 shows the age distributions of the 2,139 positive and 1,152 negative events. For positive events, we found a clear reminiscence bump, replicating Berntsen and Rubin's (2002) findings. The life span distribution of positive events was significantly different from an equal distribution $\left[\chi^{2}(4)=749.04, p<.001\right.$; 100 bootstrap samples: median $\chi^{2}(4)=182.97, p<.001$, mean $n=379$, mean Cohen's $w=0.70, S D=0.05]$ and showed invariance across the age groups $\left[\chi^{2}(8)=7.43\right.$, $p=.49 ; 100$ bootstrap samples: median $\chi^{2}(8)=7.06, p=$ .53 , mean $n=382$, mean Cramer's $V=.10, S D=.02]$.

For negative events, we expected to find history-related bumps for WWII-related events. In Austria, the Third Reich lasted from 1938 to 1945, and the war was from 1939 to 1945 . Thus, the participants less than 60 years of age in 2002, when these data were collected, were either not born or were too young to have important memories from the war era. For the participants 60-70, 70-80, and 80-90 years of age, that historical period would have mostly occurred in their first, second, and third decade of life, respectively. Significant age group differences reflecting this prediction were found in the life span distributions of negative memories $\left[\chi^{2}(8)=75.41, p<.001 ; 100\right.$ bootstrap samples: median $\chi^{2}(8)=20.54, p=.01$, mean $n=$ 224 , mean Cramer's $V=.21, S D=.03]$, and configural frequency analysis showed reminiscence bumps in the 0-10 decade for the 60- to 69-year-olds and in the 11-20 decade for the 70- to 90 -year-olds. This finding is consistent with other research showing history-related bumps by cohort for negative events (e.g., Conway \& Haque, 1999; Rubin \& Berntsen, 2003).

Except for war-related events, however, the expectation was that a reminiscence bump should not be evident for negative events. After excluding the WWII-related events (11.7\% of all negative events), the overall age frequency distribution of negative events did not differ from an equal distribution $\left[\chi^{2}(4)=7.58, p=.11 ; 100\right.$ bootstrap samples: median $\chi^{2}(4)=3.77, p=.44$, mean $n=198$, mean Cohen's $w=.15, S D=.04$; see Figure 2]. There was still a marginally significant difference in distributions between the age groups $\left[\chi^{2}(8)=20.01, p=.01\right]$; however, this difference was not significant in the 100 bootstrap samples [median $\chi^{2}(8)=10.34, p=.24$; mean $n=196$, mean Cramer's $V=.16, S D=.04]$, and configural frequency analysis did not identify any particularly over- or underrepresented cells. Thus, we also replicated Berntsen and Rubin's (2002) finding of no general reminiscence bump for participants' saddest memory with the present sample of negative events.

\section{Combining Perceived Control and Valence of Event}

For all the following analyses, war-related events were excluded. Events were coded as high perceived control if they had received a rating of 4 or 5 on the perceived control scale and as low perceived control if they had received a rating of 1 or 2 . Table 1 shows the strong association between valence and perceived control in these life events $\left[\chi^{2}(1)=1,118.06, p<.001 ; 100\right.$ bootstrap samples: median $\chi^{2}(1)=191.28, p<.001$, mean $n=486$, mean $\Phi=$ $.63, S D=.03]$. Of the positive events, $85.6 \%$ were high perceived control, and of the negative events, $78.7 \%$ were low perceived control. Due to the large sample, sufficient

Table 1

Cross-Tabulation of Valence and Perceived Control

\begin{tabular}{lccr}
\hline Valence & $\begin{array}{c}\text { Low-Perceived } \\
\text { Control }\end{array}$ & $\begin{array}{c}\text { High-Perceived } \\
\text { Control }\end{array}$ & Total \\
\hline Negative & 759 & 206 & 965 \\
Positive & 262 & 1,553 & 1,815 \\
Total & 1,021 & 1,759 & 2,780 \\
\hline
\end{tabular}

Note-Events that were rated 3 (neutral) for either valence or perceived control were excluded. 

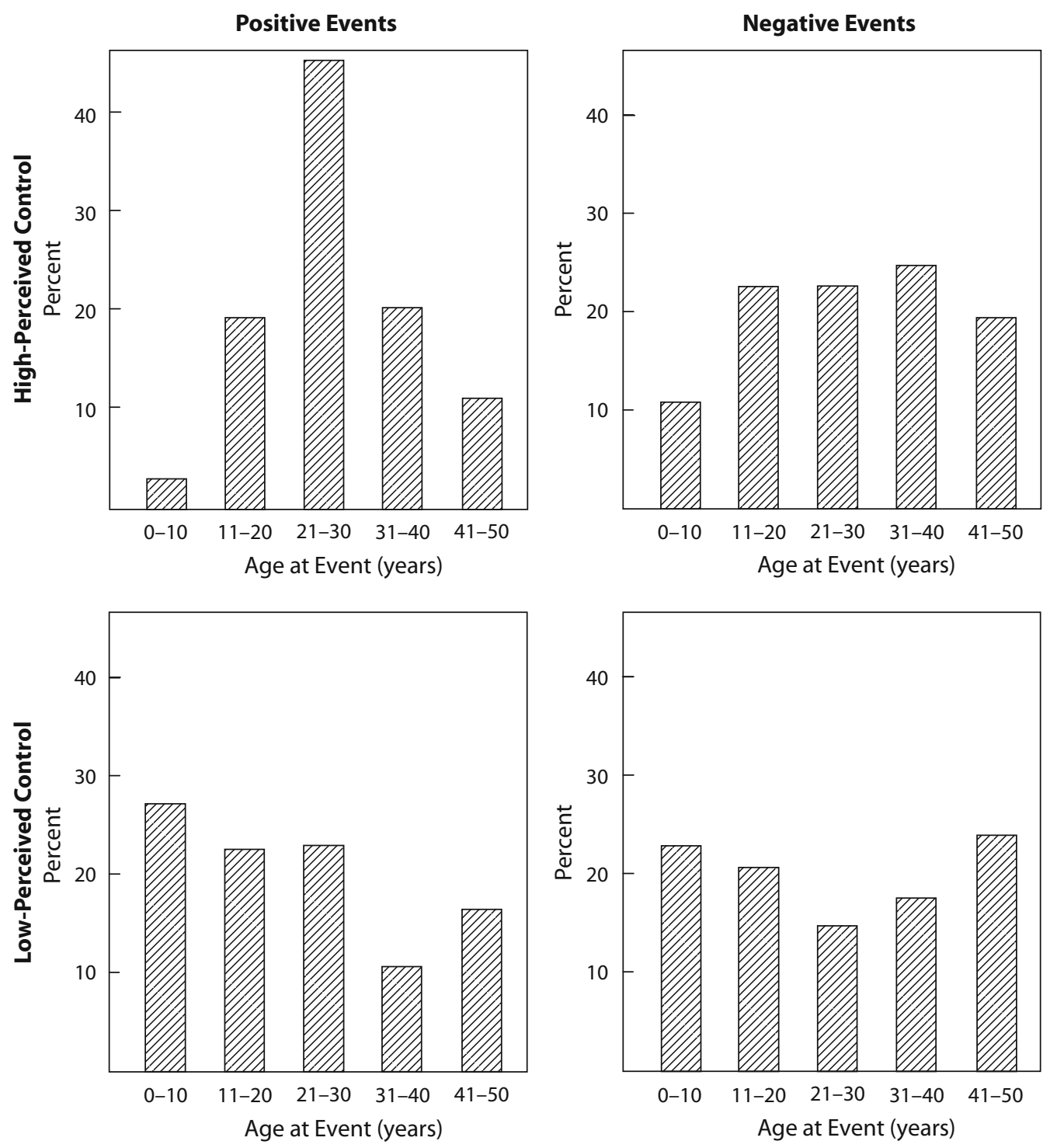

Figure 3. Life span distributions of four combinations of valence and perceived control.

numbers of low-perceived-control positive events $(n=$ 262) and high-perceived-control negative events $(n=$ 206) still permit analyses of the age distributions for all four types of events, although the sample sizes in the bootstrap samples were relatively low. The age group comparisons for these two lower frequency types of events are, therefore, less reliable. Figure 3 shows the life span distributions of the four event types. Positive/high-perceivedcontrol events are the most frequent category $(58.4 \%$ of the events). These events show a reminiscence bump with a pronounced peak in the 21-30 decade. The distribution of positive/high-perceived-control events is different from an equal distribution $\left[\chi^{2}(4)=783.37, p<.001 ; 100\right.$ bootstrap samples: median $\chi^{2}(4)=171.52, p<.001$, mean $n=279$, mean Cohen's $w=.78, S D=.05$ ], and is similar across age groups $\left[\chi^{2}(8)=9.18, p=.33 ; 100\right.$ bootstrap samples: median $\chi^{2}(8)=6.31, p=.61$, mean $n=274$, mean Cramer's $V=.11, S D=.03]$.
Positive/low-perceived-control events accounted for only $9.2 \%$ of the life events. Their distribution is different from an equal distribution $\left[\chi^{2}(4)=20.23, p<.001\right.$; 100 bootstrap samples: median $\chi^{2}(4)=10.09, p=.04$, mean $n=43$, mean Cohen's $w=.49, S D=.11$ ]. Configural frequency analysis showed a significant negative residual - that is, a reminiscence dip - in the 31- to 40year-old interval. The distribution was similar across the three age groups $\left[\chi^{2}(8)=9.573, p=.30 ; 100\right.$ bootstrap samples: median $\chi^{2}(8)=11.34, p=.18$, mean $n=43$, mean Cramer's $V=.37, S D=.07]$.

Negative/high-perceived-control events were also an infrequent category (7.1\% of all events). Their distribution is different from an equal distribution in the total sample of events $\left[\chi^{2}(4)=11.312, p=.02\right]$, but not across the 100 bootstrap samples [median $\chi^{2}(4)=3.87, p=.42$, mean $n=38$, mean Cohen's $w=.32, S D=.09$ ] and is similar across the three age groups $\left[\chi^{2}(8)=9.336, p=.32 ; 100\right.$ 


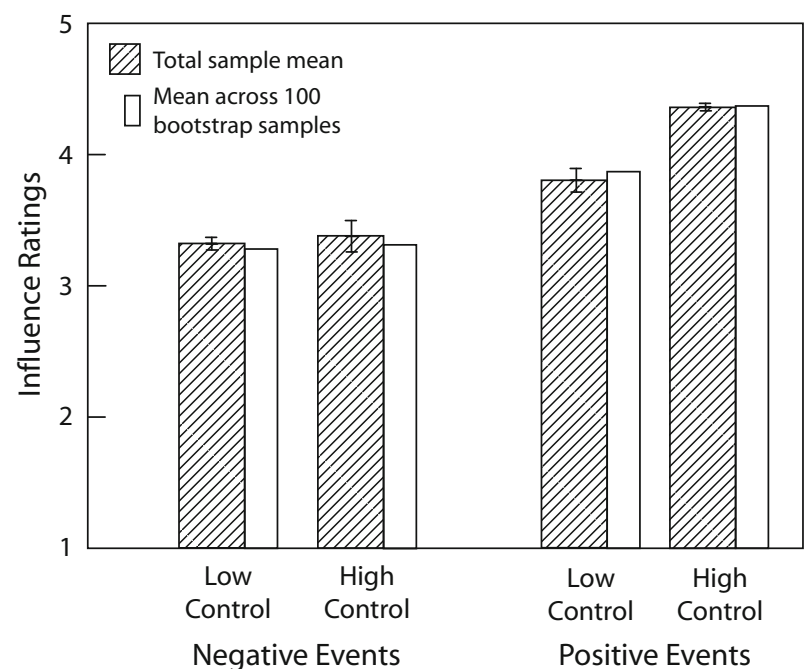

Figure 4. Mean influence ratings for four combinations of valence and perceived control.

bootstrap samples: median $\chi^{2}(8)=8.71, p=.37$, mean $n=38$, mean Cramer's $V=.34, S D=.08]$.

Negative/low-perceived-control events occurred quite frequently $(25.2 \%)$. Their distribution was significantly different from an equal distribution $\left[\chi^{2}(4)=19.104, p<\right.$ $.01]$; however, this was not the case in the 100 bootstrap samples [median $\chi^{2}(4)=5.62, p=.23$, mean $n=126$, mean Cohen's $w=.21, S D=.06]$. The distribution was not significantly different across the three age groups $\left[\chi^{2}(8)=14.516, p=.07 ; 100\right.$ bootstrap samples: median $\chi^{2}(8)=10.64, p=.22$, mean $n=124$, mean Cramer's $V=.21, S D=.04]$.

\section{Perceived Influence on Later Development}

The four types of events described above were compared with respect to participants' ratings of the events' influence on who they have become. We first conducted an ANOVA with influence as the dependent variable and valence and perceived control (both dichotomized into high and low as above) as factors. However, due to massive inhomogeneity of variances [Levene's $F(3,2615)=$ 93.22, $p<.001]$ and unequal group sizes, the ANOVA approach was not tenable, and we instead compared the four groups using a Kruskal-Wallis test. There were significant differences between the groups $\left[\chi^{2}(3)=335.91\right.$, $p<.001 ; 100$ bootstrap samples: median $\chi^{2}=65.81, p<$ .001 , mean $n=484]$.

Figure 4 shows the mean influence ratings for the four event types, both in the total sample and across the 100 bootstrap samples. Influence ratings are lower and independent of perceived control for negative events. For positive events, influence is rated higher and is specifically higher when perceived control is also rated as high. A Mann-Whitney $U$ test directly comparing the influence ratings for positive, high-perceived-control events with those for positive, low-perceived-control events showed that the difference was significant $[Z(N=1,809)=6.46$, $p<.001 ; 100$ bootstrap samples: mean $Z=2.77, p=.01$, mean $n=320]$.

\section{The Life Script Versus the Life Story}

Whereas the analyses above provide evidence for the life story account, the following analyses provide more direct evidence against the exclusive use of a life script account. Table 2 shows the events that were most frequently listed by the participants in Berntsen and Rubin's (2004) study, in which the participants generated events typically contained in life scripts. On the basis of these event categories, a total of $1,624(45.9 \%)$ of the 3,541 important life events collected in the present study were coded as scripted events. For each event category, the table shows how many participants listed an event in this category at least once. As the table shows, event category frequencies in the present study (in which the participants reported important life events), were markedly lower than those in Berntsen and Rubin's 2004 life script study; thus, people did not exclusively draw their important life events from life scripts.

We had specifically predicted that not all scripted events, but only positive, high-perceived-control scripted

Table 2

Life Script Events and Important Life Events

\begin{tabular}{|c|c|c|c|c|c|c|c|c|}
\hline & \multirow{3}{*}{$\begin{array}{c}\text { Life Script Events, } \\
\text { Frequency }\end{array}$} & \multicolumn{7}{|c|}{ Important Life Events, Present Study $(N=659)$} \\
\hline & & \multirow[b]{2}{*}{ Frequency } & \multicolumn{2}{|c|}{ Valence } & \multicolumn{2}{|c|}{ Control } & \multicolumn{2}{|c|}{ Influence } \\
\hline & & & $M$ & $S D$ & $M$ & $S D$ & $M$ & $\mathrm{SD}$ \\
\hline Having children & $93(90.3 \%)$ & $322(48.9 \%)$ & 4.77 & 0.76 & 4.06 & 1.22 & 4.31 & 1.05 \\
\hline Marriage & $77(74.8 \%)$ & $396(60.1 \%)$ & 4.59 & 0.88 & 4.37 & 0.96 & 4.30 & 1.08 \\
\hline Begin school & $68(66.0 \%)$ & $50(7.6 \%)$ & 4.20 & 1.14 & 2.71 & 1.57 & 3.67 & 1.31 \\
\hline College, etc. & $56(54.4 \%)$ & $49(7.5 \%)$ & 4.74 & 0.61 & 4.59 & 0.68 & 4.58 & 0.73 \\
\hline Fall in love & $52(50.5 \%)$ & $31(4.7 \%)$ & 4.47 & 1.19 & 3.16 & 1.32 & 3.22 & 1.41 \\
\hline Others' deaths & $32(31.1 \%)$ & $109(16.5 \%)$ & 1.18 & 0.60 & 1.83 & 1.29 & 3.42 & 1.38 \\
\hline Retirement & $31(30.1 \%)$ & $7(1.1 \%)$ & 2.67 & 1.97 & 3.57 & 1.62 & 4.29 & 1.50 \\
\hline Leave home & $26(25.2 \%)$ & $13(2.0 \%)$ & 4.69 & 0.63 & 4.54 & 0.88 & 3.77 & 1.48 \\
\hline Parents' death & $24(23.3 \%)$ & $188(28.5 \%)$ & 1.29 & 0.78 & 1.83 & 1.38 & 3.13 & 1.38 \\
\hline First job & $22(21.4 \%)$ & $126(19.1 \%)$ & 4.25 & 1.05 & 4.02 & 1.14 & 4.77 & 0.76 \\
\hline
\end{tabular}



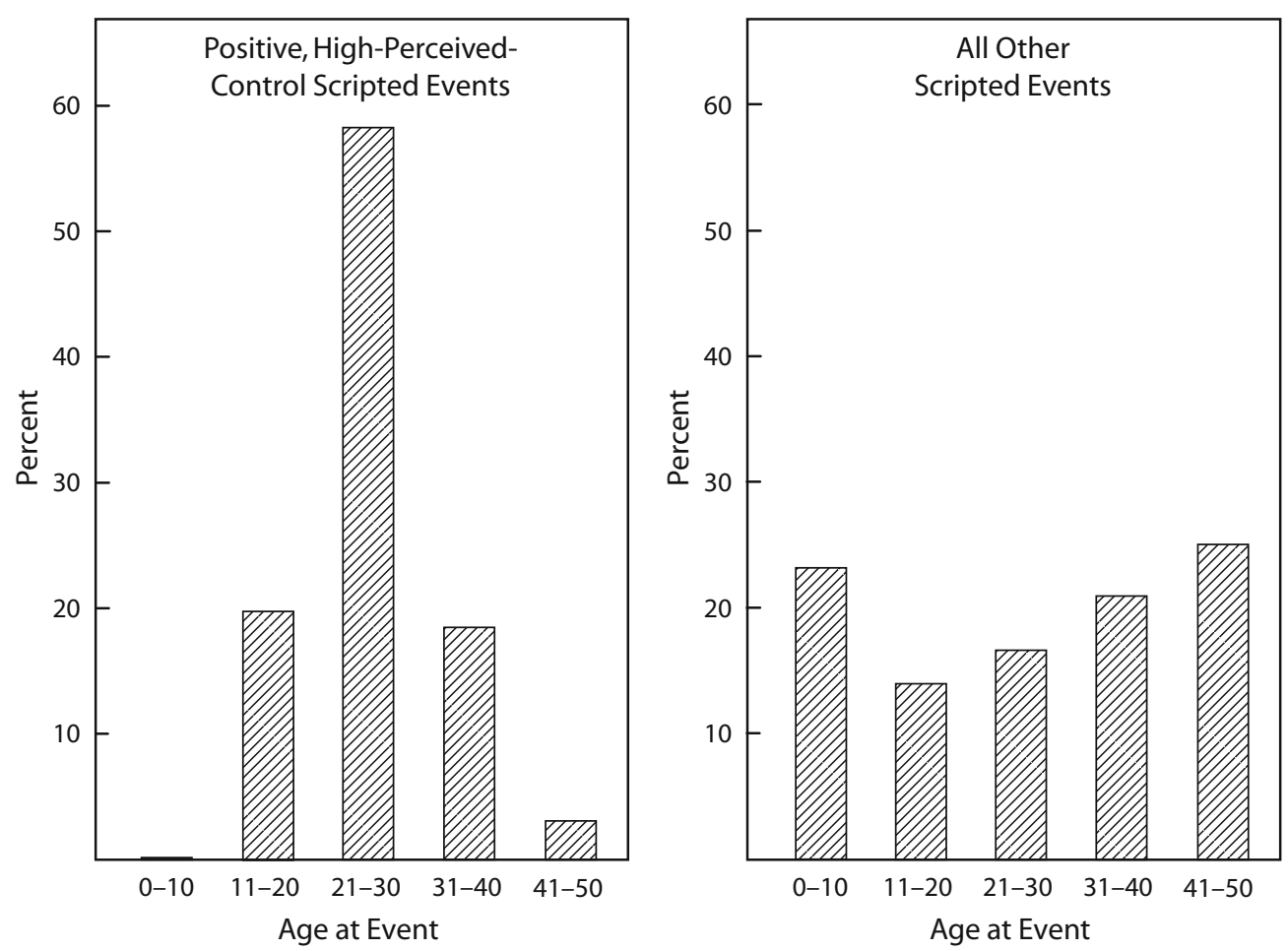

Figure 5. Life span distributions of positive, high-perceived-control scripted events and other scripted events.

events should show a reminiscence bump. An inspection of Table 2 already shows that the positive, high-perceivedcontrol scripted event categories (having children, marriage, college, falling in love, leaving home, and first job) can be related to the reminiscence bump age (i.e., late adolescence/early adulthood), whereas scripted events that were coded as either negative or neutral or as lowperceived-control events (beginning school, death of parents and other persons, and retirement) are not typical for this period of life. Accordingly, as Figure 5 shows, we found a pronounced reminiscence bump for positive, high-perceived-control scripted events and no reminiscence bump at all for other scripted events (i.e., negative or neutral or low-perceived-control scripted events). The life span distribution of positive, high-perceived-control scripted events was significantly different from an equal distribution $\left[\chi^{2}(4)=1,300.99, p<.001 ; 100\right.$ bootstrap samples: median $\chi^{2}(4)=189.72, p<.001$, mean $n=$ 242, mean Cohen's $w=1.07, S D=0.04]$. The life span distribution of all other events was different from an equal distribution $\left[\chi^{2}(4)=17.47, p<.01\right]$ in the total sample of events, but not in the 100 bootstrap samples [median $\chi^{2}(4)=3.71, p=.45$, mean $n=81$, mean Cohen's $w=$ $0.22, S D=0.07]$.

\section{DISCUSSION}

This large-scale study addressed the theoretical issue of the causes underlying the reminiscence bump. Specifically, the life story account, an extension of the life script account of the reminiscence bump proposed by Berntsen and Rubin (2002, 2004; Rubin \& Berntsen, 2003), was tested. In brief, the life script account states that when people search memory for important life events, retrieval is guided by a culturally normative life script. Since such scripts contain a high proportion of positive events between the ages of 15 and 30 years, use of this script during recall of one's happiest life events produces a reminiscence bump. Negative events are not part of the life script; thus, no reminiscence bump for such events is produced (Berntsen \& Rubin, 2002, 2004; Rubin \& Berntsen, 2003).

The present work substantially extends the life script account. On the basis of life span developmental theory and the autobiographical memory literature, the life story account postulates that the reminiscence bump consists largely of normative age-graded events in which the individual made consequential life choices in keeping with the developmental tasks of the transition to adulthood. Such events are characterized by positive valence and by a high level of perceived control. They are memorable because they act as anchoring events (Pillemer, 1998) in the life story: they are later perceived as highly influential on how the individual has developed over time. Thus, the present research suggests that although life scripts may play a role in retrieval, the developmental importance of an event and its consequences for one's individual life trajectory are also relevant. Events from the transition to adulthood are repeated and rehearsed and gradually integrated into a life story that then acts as an organizational structure for recalling and relating one's important life events (i.e., a life 
story schema; Bluck \& Habermas, 2000). The life story schema has been argued to be the most abstract level of organization in a recent model of autobiographical memory (Conway et al., 2003).

To examine the adequacy of the life story account, the present study assessed valence, perceived control, and perceived influence of the most important remembered life events $(N=3,541)$ of a sample of 659 individuals (50-90 years). Predictions that could be made from either the life script or the life story account (1 and 2) were confirmed, but importantly, the predictions based uniquely on the extended life story account ( 3 and 4 ) and that refute the exclusive use of a life script account (5) were also confirmed.

1. Positive events showed a reminiscence bump; negative events did not.

2. There were history-related bumps for negative historical events in the period in which each cohort lived through WWII.

3. Only high-perceived-control positive events showed a reminiscence bump; low-perceived-control or negative events did not.

4. These high-perceived-control positive events were viewed as significantly more influential on one's development than low-perceived-control events or negative events.

5. Among events contained in life scripts, only positive, high-perceived-control events showed a reminiscence bump.

Thus, these data suggest that the life story account has additional explanatory power. The findings will be discussed in greater detail below.

\section{Only High-Perceived-Control Positive Events Show the Reminiscence Bump}

The present data extend Berntsen and Rubin's (2002) findings that only positive events show the reminiscence bump, demonstrating that only high-perceived-control positive events showed a reminiscence bump. Lowperceived-control positive events did not. More than $50 \%$ of all the recalled events were of the positive, highperceived-control type (see Table 1). Theoretical advocates of strivings for perceived control and self-efficacy as motivators of human behavior (e.g., Bandura, 1997; Heckhausen, 1997) would perhaps argue that seeing one's self as an agent of control is what drives the inclusion of such events in individuals' life stories. That is, an event that is perceived as under the control of the individual may have a high probability of being viewed as positive and, also, of being included in the "story" of the individual as designer of his or her own life. In contrast, it may be adaptive to selectively forget, or to reappraise, high-perceived-control negative events (Wilson \& Ross, 2003). Such events are basically admissions of failure to steer the course of one's life in a positive direction. These were the least frequent category of events in the present data. Frequent recall of high-perceived-control positive events and infrequent reference to high-perceived-control negative events may allow individuals to maintain an adaptive view of life in which they are agentic and successful (Greenwald, 1980;
Ross, 1989; Wrosch \& Heckhausen, 2002). The finding that events contained in life scripts are characterized not only by positivity, but also by high perceived control does not necessarily contradict the notion of life scripts as guiding retrieval: High control might be an implicit characteristic of the events life scripts ascribe to young adulthood. ${ }^{4}$ The second part of our evidence, however, suggests that life scripts are only one among several factors guiding retrieval.

\section{Important Life Events: An Interaction of Life Script and Causal Coherence}

When attempting a theoretical account of the reminiscence bump, it is important to keep in mind that the bump is the result of a retrospective view of life. Thus, the second point of evidence for the life story account is the finding that the high-perceived-control positive events of the reminiscence bump are currently perceived as having had higher levels of influence on personal development than did all other types of important life events. Thus, the events recalled not only must have had salience at the time they occurred, but also are memorable because they are also seen as currently influential. This understanding of the influence of past events on current events or on one's development is referred to as creating causal coherence in the life story (Bluck \& Habermas, 2000). A normative life script (Berntsen \& Rubin, 2004) or cultural concept of biography (Habermas \& Bluck, 2000) may organize one's life events and, thereby, aid in retrieval. The present data suggest, however, that causal coherence in one's own biography is also necessary to integrate the events of life into a memorable chain, one in which the reminiscence bump years play an influential role. Thus, these two components presumably interact in creating an individual account of one's life.

The salience of life scripts, as compared with causal coherence, may be partly dependent on task characteristics. It seems somewhat unlikely that when asked, as in the present study, to recall the most important events of their life and to rate the influence of these events on their development, participants would draw solely upon a generalized culturally normative life script, instead of utilizing their own unique life story that incorporates their personal memories across different life phases. Life scripts may be more salient, however, when less naturalistic retrieval tasks are performed. Identifying categories such as one's happiest event (the task used by Berntsen \& Rubin, 2002), for example, requires an effortful search process (unless we assume that memory is organized in a happiness hierarchy) including decisions among candidate events that may be difficult to compare. In such a situation, individuals may utilize life scripts as a way to preselect a life phase with a high likelihood of certain event types. For that task, then, life scripts may be an important retrieval tool.

Thus, different methods of data collection may lead to differences in the type and number of retrieval strategies employed. We suggest, however, that even when people are trying to identify their happiest or saddest memories, they may rely on the life story (which includes a cultural concept of biography-i.e., a life script—but also in- 
cludes causal coherence), rather than only on a life script. This hypothesis may be an interesting starting point for future research.

\section{Conceptual Conundrums}

Several limitations exist in the present data and in both the life script and the life story accounts of the reminiscence bump. These include imprecision in predictions concerning negative events and the difficulty of disentangling actual and remembered event frequencies.

Accounting for negative events. This study showed cohort-specific reminiscence bumps related to a historical period: As was predicted, the two older age groups showed overrepresentation of negative events from the age at which they experienced the Third Reich and WWII. Content analyses confirmed that these events were indeed war related. Thus, as life span theory would suggest, bumps in life span distributions of events across individuals can result from history-graded events, as well as from normative age-graded events (see also Conway \& Haque, 1999; Rubin \& Berntsen, 2003; Schrauf \& Rubin, 2001). Aside from history-graded events, however, negative events were equally distributed over the life span in the present data. Some studies have shown decreases in negative event frequency as age of memory increases, interpreting this as a classic forgetting curve (Berntsen \& Rubin, 2002). One limitation of both the life script and the life story accounts is the lack of precise predictions about negative event distributions. The life script account postulates that life scripts do not contain a higher frequency of negative events in one life phase, so the life span distributions of remembered negative events should show a classic forgetting curve. In the life story account, predictions can be derived from life span theory. First, one could argue that nonnormative events, by definition not related to a specific life phase and thus often unexpected, are more often negative than positive. If that is true, an equal life span distribution of negative events would be expected across adulthood. Life span theory would further suggest an increased frequency of age-normative negative events in very late life (due to illness and loss of close others; see, e.g., Baltes \& Smith, 2003). Since the present sample included a relatively small number of participants over age 80 , we were unable to test whether a reminiscence bump for negative events occurs in very late life.

An additional issue, however, concerns memory (not occurrence) of negative events. Selective memory processes may create frequency distributions that differ from actual frequencies. Note that the participants in the present study recalled far fewer negative than positive events overall. Past research suggests that selective memory processes result in individuals' recalling fewer negative than positive events (Walker, Skowronski, \& Thompson, 2003), in negative events being reconstructed to appear more positive (Neisser, 1981), and in negative events fading more quickly over time (Wilson \& Ross, 2003). From the life story account, one speculation is that individuals are loathe to recall negative events as guiding their development. This may be particularly true for negative events that cannot be understood as leading to positive developmental outcomes (e.g., redemption sequences; Bluck
\& Glück, 2004; McAdams, Reynolds, Lewis, Patten, \& Bowman, 2001). This fits well with the evidence that a reminiscence bump for negative events does emerge when word-cued memories are collected (Jansari \& Parkin, 1996; Rubin \& Schulkind, 1997). Thus, negative events may be frequent in the reminiscence bump age too but are not retrieved as frequently as positive events when tasks require retrieval of important life events.

Life script, life story, or just life? One important limitation of any account of the reminiscence bump is the difficulty in comparing accounts against one another. In particular, it is difficult to contrast either the life script account or the life story account with what Berntsen and Rubin (2002) called the actual frequency account. This account assumes that the reminiscence bump simply reflects accurate recall of the actual frequency of events.

Script theory generally assumes that scripts are learned from repeated observations in life (Lockhart, 1989; Neisser, 1981; Schank \& Abelson, 1977). Thus, an individual's life script reflects a sort of probabilistic accumulation of life event data that an individual has learned (Habermas $\&$ Bluck, 2000) from observing other people's life events. If life scripts are a direct, integrated, skeletal representation of the actual frequency of events, predictions using a life script account should be highly similar to those of an actual frequency account: One is a mirror of the other.

The life story account predicts some systematic differences between objective life event data (i.e., actual event frequencies) and events reported in retrospect. Remembered life events may differ from objective life events largely due to the dynamic processes of autobiographical memory: The process of remembering emphasizes some events over others. For example, low-perceived-control events or highperceived-control negative events may objectively occur but be systematically underrepresented in memory. These predictions cannot be tested without objective data concerning the actual frequencies of events in participants' lives.

\section{Conclusion}

The life script account of the reminiscence bump (Berntsen \& Rubin, 2002, 2004; Rubin \& Berntsen, 2003) has clearly moved theory forward. The idea that individuals use a normative life script as a retrieval tool when recalling life's events provides a highly parsimonious explanation for the reminiscence bump. Although skeletal life scripts may provide one form of organization in autobiographical memory, however, we follow the maxim, "Everything should be made as simple as possible, but not one bit simpler" (attributed to Albert Einstein). We may, as social scientists, sometimes be seduced into seeking parsimony at the expense of capturing the complexity of the human mind in its organization of a lifetime of memories. With the hope of sidestepping that temptation, the present article has introduced a theoretical argument and empirical data supporting a life story account of the reminiscence bump.

\section{AUTHOR NOTE}

This article is dedicated to the memory of Paul Baltes, who taught us life span developmental theory and influenced our life stories. This 
research was partly funded by Grant QLRT-2001-00280 from the European Commission. We thank Germain Weber and all the members of the Austrian ESAW team, who supported data collection for this work, and Marie-Louise Stein and Irene Zörner for assistance in content coding. Correspondence concerning this article should be addressed to either J. Glück, Department of Psychology, Alpen-Adria University Klagenfurt, Universitätsstrasse 65-67, 9020 Klagenfurt, Austria, or S. Bluck, P.O. Box 115911, University of Florida, Gainesville, FL 32611-5911 (e-mail: judith.glueck@uni-klu.ac.at orbluck@ufl.edu).

\section{REFERENCES}

ARnetT, J. J. (2000). Emerging adulthood: A theory of development from the late teens through the twenties. American Psychologist, 55, 469-480.

Baltes, P. B., Reese, H. W., \& LipsitT, L. P. (1980). Life-span developmental psychology. Annual Review of Psychology, 31, 65-110.

Baltes, P. B., \& SMith, J. (2003). New frontiers in the future of aging: From successful aging of the young old to the dilemmas of the fourth age. Gerontology, 49, 123-135.

Bandura, A. (1997). Self-efficacy: The exercise of control. New York: Freeman.

Berntsen, D., \& Rubin, D. C. (2002). Emotionally charged autobiographical memories across the life span: The recall of happy, sad, traumatic, and involuntary memories. Psychology \& Aging, 17, 636-652.

Berntsen, D., \& Rubin, D. C. (2004). Cultural life scripts structure recall from autobiographical memory. Memory \& Cognition, 32, 427-442.

BLUCK, S., \& GLÜCK, J. (2004). Making things better and learning a lesson: Experiencing wisdom across the lifespan. Journal of Personality, 72, 543-572.

Bluck, S., \& Habermas, T. (2000). The life story schema. Motivation \& Emotion, 24, 121-147.

Bluck, S., \& Habermas, T. (2001). Extending the study of autobiographical memory: Thinking back about life across the life span. Review of General Psychology, 5, 135-147.

Cohen, G., \& Faulkner, D. (1988). Life span changes in autobiographical memory. In M. M. Gruneberg, P. E. Morris, \& R. N. Sykes (Eds.), Practical aspects of memory: Current research and issues. Vol. 1: Memory in everyday life (pp. 277-282). New York: Wiley.

Conway, M. A., \& HaQue, S. (1999). Overshadowing the reminiscence bump: Memories of a struggle for independence. Journal of Adult Development, 6, 35-44.

Conway, M. A., Singer, J. A., \& Tagini, A. (2003). The self and autobiographical memory: Correspondence and coherence. Social Cognition, 22, 491-529.

Crovitz, H. F., \& Schiffman, H. (1974). Frequency of episodic memories as a function of their age. Bulletin of the Psychonomic Society, 4, 517-518.

de Vries, B., Blando, J. A., \& Walker, L. J. (1995). An exploratory analysis of the content and structure of the life review. In B. K. Haight \& J. D. Webster (Eds.), The art and science of reminiscing: Theory, research, methods, and applications (pp. 123-137). Washington, DC: Taylor \& Francis.

DE VRIES, B., \& WatT, D. (1996). A lifetime of events: Age and gender variations in the life story. International Journal of Aging \& Human Development, 42, 81-102.

Dreher, E., \& Dreher, M. (1991). Entwicklungsrelevante Ereignisse aus der Sicht von Jugendlichen [Developmentally relevant events from the perspective of adolescents]. Schweizerische Zeitschrift für Psychologie, 50, 24-33.

Elder, G. H., JR. (1998). The life course as developmental theory. Child Development, 69, 1-12.

FitzGerald, J. M. (1996). Intersecting meanings of reminiscence in adult development and aging. In D. C. Rubin (Ed.), Remembering our past: Studies in autobiographical memory (pp. 360-383). Cambridge: Cambridge University Press.

Fromholt, P., \& Larsen, S. F. (1991). Autobiographical memory in normal aging and primary degenerative dementia (dementia of Alzheimer type). Journals of Gerontology, 46B, P85-P91.

Fromholt, P., \& Larsen, S. F. (1992). Autobiographical memory and life-history narratives in aging and dementia (Alzheimer type). In M. A. Conway, D. C. Rubin, H. Spinnler, \& W. Wagenaar (Eds.), Theoretical perspectives on autobiographical memory (pp. 413-426). Utrecht: Kluwer.

Greenwald, A. G. (1980). The totalitarian ego: Fabrication and revision of personal history. American Psychologist, 35, 603-618.

Habermas, T., \& Bluck, S. (2000). Getting a life: The emergence of the life story in adolescence. Psychological Bulletin, 126, 748-769.

HavighUrst, R. J. (1952). Developmental tasks and education. New York: MacKay.

Heckhausen, J. (1997). Developmental regulation across adulthood: Primary and secondary control of age-related challenges. Developmental Psychology, 33, 176-187.

Hooker, K., \& McAdams, D. P. (2003). Personality reconsidered: A new agenda for aging research. Journals of Gerontology, 58B, P296-P304.

Jansari, A., \& Parkin, A. J. (1996). Things that go bump in your life: Explaining the reminiscence bump in autobiographical memory. Psychology \& Aging, 11, 85-91.

Lachman, M. E., \& FirTh, K. M. P. (2004). The adaptive value of feeling in control during midlife. In O. G. Brim, C. D. Ryff, \& R. C. Kessler (Eds.), How healthy are we? A national study of well-being at midlife (pp. 320-349). Chicago: University of Chicago Press.

LeVinson, D. (1986). A conception of adult development. American Psychologist, 41, 3-13.

LOCKHART, R. S. (1989). Consciousness and the function of remembered episodes. In H. L. Roediger III \& F. I. M. Craik (Eds.), Varieties of memory and consciousness (pp. 423-430). Hillsdale, NJ: Erlbaum.

Martin, P., \& Smyer, M. A. (1990). The experience of micro- and macroevents: A life span analysis. Research on Aging, 12, 294-310.

MAYER, K. U. (2001). The paradox of global social change and national path dependencies: Life course patterns in advanced societies. In A. Woodward \& M. Kohli (Eds.), Inclusions and exclusions in European societies (pp. 89-110). London: Routledge.

McAdams, D. P. (1993). Stories we live by: Personal myths and the making of the self. New York: Morrow.

McAdams, D. P., Reynolds, J., Lewis, M., Patten, A. H., \& Bowman, P. J. (2001). When bad things turn good and good things turn bad: Sequences of redemption and contamination in life narrative and their relation to psychosocial adaptation in midlife adults and in students. Personality \& Social Psychology Bulletin, 27, 474-485.

NeIsSER, U. (1981). John Dean's memory: A case study. Cognition, 9, $1-22$.

Neugarten, B. L. (1968). Adult personality: Toward a psychology of the life cycle. In B. L. Neugarten (Ed.), Middle age and aging: $A$ reader in social psychology (pp. 137-147). Chicago: University of Chicago Press.

Neugarten, B. L., \& Hagestad, G. O. (1976). Age and the life course. In R. Binstock \& E. Shanas (Eds.), Handbook of aging and the social sciences (pp. 35-55). New York: Van Nostrand Reinhold.

Pillemer, D. B. (1998). Momentous events, vivid memories. Cambridge, MA: Harvard University Press.

RAPPAPORT, H., ENRICH, K., \& Wilson, A. (1985). Relation between ego identity and temporal perspective. Journal of Personality \& Social Psychology, 48, 1609-1620.

Riley, M. W. (1987). On the significance of age in sociology. American Sociological Review, 52, 1-14.

Ross, M. (1989). The relation of implicit theories to the construction of personal histories. Psychological Review, 96, 341-357.

RuBin, D. C. (2002). Autobiographical memory across the lifespan. In P. Graf \& N. Ohta (Eds.), Lifespan development of human memory (pp. 159-184). Cambridge, MA: MIT Press.

Rubin, D. C., \& Berntsen, D. (2003). Life scripts help to maintain autobiographical memories of highly positive, but not highly negative, events. Memory \& Cognition, 31, 1-14.

Rubin, D. C., Rahhal, T. A., \& Poon, L. W. (1998). Things learned in early adulthood are remembered best. Memory \& Cognition, 26, 3-19.

Rubin, D. C., \& Schulkind, M. D. (1997). The distribution of autobiographical memories across the lifespan. Memory \& Cognition, 25, 859-866. 
Rubin, D. C., Wetzler, S. E., \& Nebes, R. D. (1986). Autobiographical memory across the adult lifespan. In D. C. Rubin (Ed.), Autobiographical memory (pp. 202-221). New York: Cambridge University Press.

Schank, R. C., \& Abelson, R. P. (1977). Scripts, plans, goals, and understanding: An inquiry into human knowledge structures. Hillsdale, NJ: Erlbaum.

Schrauf, R. W., \& Rubin, D. C. (2001). Effects of voluntary immigration on the distribution of autobiographical memory over the lifespan. Applied Cognitive Psychology, 15, S75-S88.

Singer, J. A., \& BlUCK, S. (2001). New perspectives on autobiographical memory: The integration of narrative processing and autobiographical reasoning. Review of General Psychology, 5, 91-99.

Walker, W. R., Skowronski, J. J., \& Thompson, C. P. (2003). Life is pleasant-and memory helps to keep it that way! Review of General Psychology, 7, 203-210.

Weber, G., Glück, J., Schäfer, L., Wehinger, K., Heiss, C., \& SASSENRATH, S. (2005). ESAW-Europäische Studie zum Wohlbefinden im Alter: Hauptergebnisse unter besonderer Berücksichtigung der Situation in Österreich [ESAW-European study of adult well-being: Main findings, particularly concerning the situation in Austria.] Vienna: WUV.

Wilson, A., \& Ross, M. (2003). The identity function of autobiographical memory: Time is on our side. Memory, 11, 137-150.

Wrosch, C., \& Freund, A. M. (2001). Self-regulation of normative and non-normative developmental challenges. Human Development, 44, 264-283.

Wrosch, C., \& Heckhausen, J. (2002). Perceived control of life regrets: Good for young and bad for old adults. Psychology \& Aging, 17, 340-350.

\section{NOTES}

1. One variation is that the reminiscence bump for word-cued events is located somewhat earlier in the life span (10-30 years of age) than is the bump for important events (20-30) (see, e.g., Rubin, 2002).

2. Note that over the last few decades, a major destandardization of life trajectories has taken place in Western societies (e.g., Mayer, 2001; Wrosch \& Freund, 2001); the phase from age 18 to 25 has become a period of exploration rather than decision ("emerging adulthood"; Arnett, 2000). Thus, reminiscence bump data that will be collected 20 years from now in individuals who are now 20-30 years old will possibly look different than the data we find today. Still, even Arnett observes that "by the end of . . the late twenties, most people have made life choices that have enduring ramifications" (p. 469).

3. These numbers do not add up to 5,293 , because some events fulfilled more than one exclusion criterion.

4. This idea may be supported by the fact that the list of scripted events from Berntsen and Rubin (2004) does not contain any low-perceivedcontrol positive scripted events. If life scripts do not contain lowperceived-control positive events, high perceived control might indeed be characteristic of all positive events contained in life scripts. We do not believe that this is the case, however: The most frequent content among low-perceived-control positive events in our data is childbirth, mostly concerning birth of a grandchild. Although Berntsen and Rubin (2004) did not find this category in their data, it would seem typical enough to be part of a life script, and it would certainly not show a reminiscence bump in young adulthood (our data suggest a bump in the $50 \mathrm{~s}-70 \mathrm{~s}$ ).

(Manuscript received June 26, 2006; revision accepted for publication April 10, 2007.) 